\title{
The impact of self-control cues on subsequent monetary risk-taking
}

\author{
DAMIEN BREVERS ${ }^{1,2} *$, JENNIFER FOUCART ${ }^{2}$, OFIR TUREL $^{3,4}$, ANAIS BERTRAND $^{1}$, MIKAEL ALAERTS $^{1}$, \\ PAUL VERBANCK ${ }^{1,2}$, CHARLES KORNREICH $^{1}$ and ANTOINE BECHARA ${ }^{4}$ \\ ${ }^{1}$ Laboratory of Psychological Medicine and Addictology, Faculty of Medicine, CHU-Brugmann, Université Libre de Bruxelles, \\ Brussels, Belgium \\ ${ }^{2}$ Research in Psychology Applied to Motor Learning, Faculty of Motor Sciences, Université Libre de Bruxelles, Brussels, Belgium \\ ${ }^{3}$ College of Business and Economics, California State University, Fullerton, CA, USA \\ ${ }^{4}$ Department of Psychology, and Brain and Creativity Institute, University of Southern California, Los Angeles, CA, USA
}

(Received: May 30, 2018; revised manuscript received: July 28, 2018; second revised manuscript received: August 10, 2018; accepted: August 30, 2018)

\begin{abstract}
Background and aims: The "process-model" of self-control proposes that the ego-depletion effect is better explained by a switch between interest in "have-to" labor and cognitive "want-to" leisure, rather than being mainly due to a decrease in cognitive resources, as advanced by the "strength-model" of self-control. However, it is currently difficult to disentangle the "process-model" from the "strength-model" of self-control. Here, we employed a stepwise approach, featuring three studies, for testing the process model of self-control. Methods: In Study 1, we created a list of 30 self-control events for characterizing "have-to" conducts in the daily life. In Study 2, mental visualization of effortful self-control events ("have-to") and monetary risk-taking ("want-to") were employed for testing the strengthmodel of self-control. In Study 3, to test the process-model of self-control, participants were simply required to read self-control (or neutral) sentences. Results: Study 1 provided evidence regarding external validly for the list of selfcontrol events. Study 2 showed that mental visualization of effortful self-control events increases subsequent monetary risk-taking. Study 3 highlighted that the brief apparition of a self-control-related sentence was sufficient for increasing risk-taking. These patterns were evidenced in the trial with the less advantageous gain/loss ratio. Discussion: Altogether these findings support the process-model of self-control in showing that triggering the semantic content of a "have-to" conduct, without its actual execution, is sufficient for modulating subsequent "wantto" activity. Conclusion: These findings could contribute to advancing current knowledge on how the high availability of ready-to-consume rewards in modern environments is redefining humans' self-control ability.
\end{abstract}

Keywords: self-control, ego-depletion, strength-model, process-model, gambling

\section{INTRODUCTION}

Self-control refers to one's capacity to favor his or her abstract and distal goals when they are threatened by competing concrete and proximal goals (Baumeister, Bratslavsky, Muraven, \& Tice, 1998; Baumeister, Vohs, \& Tice 2007; Fujita, 2011; Tangney, Baumeister, \& Boone, 2004). This requires from the individual the effortful override of thoughts, emotions, or impulses associated with inappropriate behaviors that produce strong immediate rewards, so that he or she could engage in behaviors that are consistent with desirable long-term goals that are often less rewarding in the near future (Baumeister et al., 2007).

Baumeister's influential strength-model advances that self-control restraint relies on a limited resource equated with a muscle (Baumeister et al., 1998, 2007). This model posits that engaging in self-control quickly consumes one's limited resource or energy leaving him or her in a state of "ego-depletion." Consequently, when individuals engage in an effortful activity at Time 1, ability to exert self-control temporarily diminishes and consequently performance on a different task at Time 2 typically deteriorates (for metaanalyses, see Hagger, Wood, Stiff, \& Chatzisarantis, 2010). Crucially, in this depleted state, further self-control attempts are prone to fail, as demonstrated across situations. For example, self-control efforts at Time 1 result in a higher tendency for eating unhealthy food (e.g., Baumeister et al., 1998; Salmon, Adriaanse, Fennis, De Vet, \& De Ridder, 2016), taking financial risks (Fischer, Kastenmüller, \& Asal, 2012; Macrae et al., 2014; Schmeichel, Harmon-Jones, \& Harmon-Jones, 2010), or at pursuing impulsive choices (Blain, Hollard, \& Pessiglione, 2016; Nolet, Rouleau, Benbouriche, Carrier Emond, \& Renaud, 2015).

* Corresponding author: Damien Brevers, PhD; Chargé de Recherche, FNRS, Laboratory of Psychological Medicine and Addictology, Faculty of Medicine, CHU-Brugmann, Université Libre de Bruxelles, Place Van Gehuchten, 4, 1020, Brussels, Belgium; Phone: +32 2473 130; Fax: +32 247721 62; E-mail: dbrevers@ulb.ac.be

This is an open-access article distributed under the terms of the Creative Commons Attribution-NonCommercial 4.0 International License, which permits unrestricted use, distribution, and reproduction in any medium for non-commercial purposes, provided the original author and source are credited, a link to the CC License is provided, and changes - if any - are indicated. 
Inzlicht and colleagues recently challenged the strengthmodel of self-control by questioning the fact that egodepletion is exclusively induced by a short-term loss of mental energy (Inzlicht \& Schmeichel, 2012; Inzlicht, Schmeichel, \& Macrae, 2014). This theoretical account instead proposes a "process-model," which advances the idea that self-control failure is less about resource depletion, but more about the switching of task priorities from a "have-to" (i.e., tasks that are carried out through a sense of duty or contractual obligation and are often difficult to execute) to a "want-to" goal (i.e., tasks that are psychologically and physically enjoyable and/or easy to perform; Hockey \& Earle, 2006; Inzlicht \& Schmeichel, 2012; Inzlicht et al., 2014; Kiesel et al., 2010). As such, egodepletion should reflect individuals' effort at maintaining a balance between cognitive labor and cognitive leisure (Inzlicht et al., 2014; also see Goldfarb \& Henik, 2014; Kool \& Botvinick, 2014). In this context, ego-depletion stems from the individual tendency to switch from mentally demanding tasks to more rewarding (or less effortful) activities. Accordingly, it has been shown that effortful cognitive control is intrinsically aversive (Botvinick, 2007; Kool \& Botvinick, 2014; Kool, McGuire, Rosen, \& Botvinick, 2010) and less frequently used when low-effort cognitive strategies (Goldfarb \& Henik, 2007, 2013) or alternative beneficial habits (Duckworth, Gendler, \& Gross, 2016; Galla \& Duckworth, 2015) can be used. Offsetting this pattern, increasing motivation or preparation to perform effortful mental activities decreases their averseness and counteracts the desire for cognitive leisure (Alberts, Martijn, \& de Vries, 2011; Converse \& Deshon, 2009; Kiesel et al., 2010; Kool et al., 2010; Muraven \& Slessareva, 2003; Moller, Deci, \& Ryan, 2006).

However, these findings do not necessarily preclude the possibility that ego-depletion could also be due to a diminution of cognitive resources. Indeed, both decreases in selfcontrol abilities after effortful self-control activity (i.e., the strength-model of ego-depletion) and in the motivation to engage in further effortful work (i.e., the process-model of ego-depletion) could contribute to the modulation of performance on subsequent tasks (e.g., Dang, Xiao, \& Dewitte, 2014). Hence, current findings do not allow to disentangle the "process-model" from the "strength-model" of self-control. Here, we present the results of three studies that can serve as a basis for doing so. As such, this study can serve as a springboard for future research that aimed at refining and setting boundaries for the aforementioned theories.

In Study 1, we created a list of 30 self-control events that should characterize "have-to" conducts in the daily life of college students (i.e., behaviors that require effortful control in order to reach valuable goals; see Galla \& Duckworth, 2015; Imhoff, Schmidt, \& Gerstenberg, 2014). The objective of Study 1 was to demonstrate sufficient external validity of the list of self-control events, before using these items in Studies 2 and 3 . Specifically, because self-control has often been negatively associated with impulsivity (e.g., Johnson, Carver, Mulé, \& Joormann, 2013; Miller et al., 2009; Tsukayama, Duckworth, \& Kim, 2012, 2013), we expect the average scores of frequency and difficulty of daily-life self-control events to be associated with the UPPS [urgency, premeditation (lack of), perseverance (lack of), sensation seeking] Impulsive Behavior Scale and its four dimensions (Whiteside \& Lynam, 2001).

Next, in Study 2, we used the self-control events from Study 1 to test the strength-model of self-control (i.e., Study 2 was not designed to differentiate between the strength-model and the process-model). Specifically, mental visualization of effortful self-control events ("have-to") and monetary risktaking ("want-to") were employed for inducing effortful activity at Time 1 and for assessing task performance at Time 2, respectively (Carr \& Steele, 2010; Fischer et al., 2012; Macrae et al., 2014; Schmeichel et al., 2010). The mental visualization of effortful events was employed for inducing effortful activity at Time 1 based on previous research that used comparable methods for simulating selfcontrol (e.g., Macrae et al., 2014). Indeed, mental simulations (e.g., reflection on running) trigger the same sensorimotor processes that operate during the actual execution of the imagined activity (Moulton \& Kosslyn, 2009). Hence, just as self-control can be used in real time to prevent an unwanted outcome (Wegner, 1994), it can be simulated offline through the mental imaginary of the self-control events (Wilson, 2002). It follows that ego depletion effects could also arise from the imagination of effortful self-control events at Time 1 (Macrae et al., 2014). Another main aspect of study 2 is that we used monetary risk-taking (i.e., gambling) as an index of "want-to" activity, that is, an equivalent to doing something that is easier or more pleasurable activity. This selection was based on previous studies that used monetary risk-taking as a leisure conduct that could produce strong immediate rewards (Carr \& Steele, 2010; Schmeichel et al., 2010), and showed that participants spent more money after they undertook selfcontrol-related conducts. We hypothesized that as compared to mental simulations of neutral events, the imagination of effortful self-control (at Time 1) would increase monetary risk-taking (at Time 2).

Finally, based on the findings from the first two studies, Study 3 aimed at testing the process-model of self-control. Specifically, we employed the same procedure as in Study 2, with one exception: participants were simply required to read self-control (or neutral) sentences. This procedure was used to examine whether triggering the semantic content of daily-life self-control events could increase monetary risktaking. We hypothesized that as compared to reading neutral events, the brief reading of sentences describing effortful self-control (at Time 1) would increase monetary risk-taking (at Time 2). Findings supporting this assumption would be in line with the process-model of self-control in showing that triggering the semantic content of a "have-to" conduct, without its actual enactment, is sufficient for modulating subsequent "want-to" activity.

\section{STUDY 1 - METHODS}

\section{Participants}

Sixty-seven undergraduate students (19-33 years of age; mean $=20.83, S D=2.87 ; 54$ males) were recruited from the Faculty of Motor Science of the Université Libre de Bruxelles (ULB). 


\section{Measures}

Daily-life self-control behaviors. Based on Imhoff et al. (2014), a list of 30 common daily-life behaviors requiring self-control were created. It contained events in which individuals have to either resist a short-term temptation (e.g., "to study instead of going out with friends") or undertake short-term effort in order to reach long-term goals (e.g., "to stretch thoroughly after a run;" see full list of sentences in Table 1). For each sentence, we assessed the frequency and difficulty of the behavior by asking: "How often do you undertake the following behavior?" on a scale from 1 (never) to 5 (very often), and "How difficult is it for you to undertake the following behavior?" on a scale from 1 (not at all) to 5 (a lot), respectively. Participants were asked not to provide difficulty ratings for behaviors that they have never undertaken (by circling "not applicable;" see also Table 1 for the percentage of "not applicable" answers for each item, across all participants).

Trait self-control. Participants completed the 13-item of the French version of the Brief Self-Control Scale (BSCS; Brevers, Foucart, Verbanck, \& Turel, 2017; Tangney et al., 2004). Items (e.g., "I am good at resisting temptation") were endorsed on a 5-point scale, where $1=$ not at all like $m e$ and
$5=$ very much like me. Cronbach's $\alpha$ was .81 . Consequently, an average scale score was calculated (with higher scores indicating better self-control).

Impulsivity. We assessed self-reported impulsivity using the French version of the UPPS (Van der Linden et al., 2006). The UPPS captures four dimensions (subscales) of impulsivity using 45 items: "urgency," defined as the tendency to experience strong reactions under the condition of intense negative affect; "lack of premeditation," describing a tendency not to consider the consequences of an act before engaging in that act; "lack of perseverance," encapsulating inability to remain focused on a task that may be boring and/or difficult; and "sensation seeking," capturing a tendency to prefer and pursue activities that are stimulating or exciting coupled with openness to trying new and unconventional experiences.

\section{Ethics}

All procedures performed in studies involving human participants were in accordance with the 1964 Helsinki Declaration and its later amendments or comparable ethical standards. Each participant gave informed consent to the experimental procedure, which was approved by the institutional review board of ULB.

Table 1. Self-control cue events used in the experiments

\begin{tabular}{|c|c|c|c|c|c|}
\hline \multirow[b]{2}{*}{ Items } & \multicolumn{2}{|c|}{ Frequency } & \multicolumn{2}{|c|}{ Difficulty } & \multirow[b]{2}{*}{$\%$ NAs } \\
\hline & $M$ & $S D$ & $M$ & $S D$ & \\
\hline To study instead of going out with friends & 3.06 & 1.10 & 2.98 & 1.24 & 2.99 \\
\hline To buy a fruit instead of a candy & 3.49 & 1.16 & 2.20 & 1.15 & 11.95 \\
\hline To study instead of going on the Internet & 3.17 & 1.02 & 3.26 & 1.14 & 1.49 \\
\hline To study instead of watching a TV show & 3.03 & 1.09 & 2.98 & 1.25 & 7.47 \\
\hline To go to bed early instead of going out with friends & 3.15 & 1.21 & 2.56 & 1.22 & 4.48 \\
\hline To go running despite bad weather & 2.48 & 1.42 & 2.80 & 1.51 & 26.87 \\
\hline To go to bed early instead of watching a TV show & 2.81 & 1.37 & 2.62 & 1.44 & 10.45 \\
\hline To chose a healthy meal instead of a tasty but fatty meal & 3.58 & 1.04 & 2.51 & 1.18 & 0.00 \\
\hline To buy water instead of a soda & 3.91 & 1.20 & 1.78 & 1.05 & 4.48 \\
\hline To buy food for cooking instead of a ready-to-eat meal & 4.00 & 1.30 & 1.81 & 1.09 & 5.98 \\
\hline To decide to turn down a cigarette offer & 3.53 & 1.64 & 1.88 & 1.40 & 32.84 \\
\hline To decide not to drink alcohol at a party & 2.37 & 1.27 & 2.76 & 1.42 & 28.36 \\
\hline To decide to turn down a dessert offer & 2.90 & 1.37 & 2.24 & 1.25 & 31.46 \\
\hline To decide to postpone my cigarette break & 1.93 & 1.45 & 1.63 & 1.12 & 67.16 \\
\hline To go to class instead of going out for a drink & 3.36 & 1.48 & 2.04 & 1.14 & 10.44 \\
\hline To go exercising instead of going out with friends & 3.19 & 1.13 & 2.60 & 1.06 & 7.46 \\
\hline To do some cleaning instead of watching TV & 3.09 & 1.22 & 2.35 & 1.11 & 7.46 \\
\hline To take notes in class instead of daydreaming & 3.21 & 1.13 & 2.83 & 1.14 & 0.14 \\
\hline To decide to take out the clean dishes from the dishwasher & 3.43 & 1.28 & 1.96 & 1.13 & 13.43 \\
\hline To decide to renew my public transport monthly pass & 2.68 & 1.39 & 1.62 & 1.01 & 11.94 \\
\hline To resist eating a plate with meat & 2.30 & 1.40 & 2.32 & 1.41 & 47.76 \\
\hline To classify documents instead of going on the Internet & 2.92 & 1.22 & 2.44 & 1.21 & 0.06 \\
\hline To take out my pet instead of watching TV & 1.96 & 1.46 & 1.31 & 0.74 & 88.08 \\
\hline To make my lunch instead of buying a sandwich & 2.99 & 1.23 & 2.78 & 1.27 & 16.41 \\
\hline To wake up instead of pressing the "snooze" button & 3.30 & 1.36 & 2.27 & 1.24 & 10.44 \\
\hline To pay attention in classes instead of talking with friends & 3.11 & 1.46 & 3.31 & 1.62 & 17.91 \\
\hline To thoroughly stretch after a run & 3.32 & 1.09 & 2.91 & 1.21 & 0.29 \\
\hline To take the stairs instead of the elevator & 3.55 & 1.27 & 2.25 & 1.26 & 7.46 \\
\hline To wait until dinner before eating & 3.56 & 1.27 & 2.00 & 1.02 & 7.46 \\
\hline To decide to read a book instead of going on the Internet & 3.21 & 1.26 & 2.70 & 1.32 & 8.95 \\
\hline
\end{tabular}

Note. Frequency and difficulty scores are taken from Study 1 only. All item scores ranged between 1 (minimum) and 5 (maximum). M: mean, $S D$ : standard deviation. \% NAs: percentage of "not applicable" answers for each item (across all participants from Study 1, $N=67$ ). 


\section{RESULTS AND DISCUSSION}

The frequency (Cronbach's $\alpha=.76)$ and difficulty $(\alpha=.86)$ aspects of daily-life self-control behaviors were sufficiently consistent across 30 events on the list. We therefore averaged scores across 30 items to obtain mean scores of frequency and difficulty of typical self-control behaviors (see Table 1 for means and standard deviations of frequency and difficulty ratings for each of the 30 items.). Pearson's correlation between these two scales was negative and significant, $r(67)=-.42, p<.001$.

Moderate correlation coefficients were observed between the index of frequency of daily-life self-control, lack of perseverance $[r(67)=-.36, p<.05]$, and urgency $[r(67)=$ $-.31, p<.05]$, indicating that the higher the frequency of daily-life self-control behaviors, the lower the lack of perseverance and level of urgency. No significant correlations were observed between the index of frequency of daily-life selfcontrol and trait self-control, $r(67)=.15$; self-reported scores of lack of premeditation, $r(67)=-.15$, ns; and sensation seeking, $r(67)=.03$, ns. Several moderate to large correlation coefficients were observed with the index of difficulty of daily-life self-control behaviors, indicating that the higher the difficulty of daily-life self-control behaviors, the lower trait self-control, $r(67)=-.41, p<.01$, and the higher self-reported scores of urgency, $r(67)=.44, p<.01$; lack of premeditation, $r(67)=.33, p<.05$; and lack of perseverance, $r(67)=.49, p<.01$. All $p$ values were adjusted for multiple comparisons with Bonferroni correction.

Altogether, these findings suggest that the index of difficulty of daily-life self-control behaviors has a higher level of face validity than the index of frequency, as it correlates with the BSCS and three UPPS subscales. Therefore, the index of difficulty was used in Studies 2 and 3 for selecting individualized self-control behaviors.

In addition, an exploratory correlation analysis revealed moderate to large correlation coefficients between trait self-control and impulsivity, indicating that the higher trait self-control was, the lower the self-reported scores of impulsivity [urgency: $r(67)=-.51, p<.001$; lack of premeditation: $r(67)=-.38, p<.01$; lack of perseverance: $r(67)=-.61, p<.001$; and sensation seeking: $r(67)=-.47$, $p<.001]$ were. This pattern is consistent with both the theoretical approach of self-control and previous findings on the relationships between impulsivity and trait selfcontrol (e.g., Johnson et al., 2013; Miller et al., 2009; Tsukayama et al., 2012, 2013).

\section{STUDY 2 - METHODS}

\section{Participants}

Eighty undergraduate students (different from those who participated in Study 1) were recruited from the Faculty of Motor Science of the ULB. Participants were randomly assigned to the neutral $(n=40)$ or self-control $(n=40)$ gambling task conditions (see Table 2 for participants' characteristics.). This sample size was matched to the highest sample size used in previous studies examining the impact of ego-depletion on financial risk-taking (Schmeichel et al., 2010).

\section{Measures}

\section{Selection of cue events.}

Self-control condition. Cue events for this condition were selected from the list of 30 self-control behaviors detailed in Study 1. Specifically, five sentences were selected, based on the highest score of difficulty obtained from a preliminary session in order to individualize cue events presented to each participant.

Neutral condition. Cue events used in the neutral condition were sentences referring to daily-life objects that do not involve any direct action from the individual (e.g., "an office table that includes two chairs" and "a building that has five floors"). The neutral sentences were the same across all participants. The list of sentences is given in Table 3 .

The gambling task and experimental conditions. We used a Coin-Flipping Task adapted from Carr and Steele (2010). Participants were presented with five coin-toss trials featuring the following gain/loss ratios: 6(gain)/2(loss) [expected value $(\mathrm{EV})=2$ ] $, 6 / 3(\mathrm{EV}=1.5), 6 / 4(\mathrm{EV}=1)$, $6 / 5(\mathrm{EV}=0.5)$, or $6 / 6(\mathrm{EV}=0)$. Each trial was divided into three stages: cue event presentation, gamble presentation, and gamble decision. Importantly, the five trials were presented in the following EV-centered succession order: $6 / 2$ $(\mathrm{EV}=2), 6 / 5(\mathrm{EV}=0.5), 6 / 6(\mathrm{EV}=0), 6 / 4(\mathrm{EV}=1)$, and $6 / 3(E V=1.5)$. This was done to prevent choices from being driven by the anticipation of trial-order succession that might induce, for instance, strategic, or sequential patterns of decision-making in some participants.

Cue event presentation. After having pressed the space bar of the keyboard, participants first viewed a short sentence on the computer screen during $4 \mathrm{~s}$ and had to read it carefully. After $4 \mathrm{~s}$, a black screen appeared and the participants were instructed to close their eyes for $30 \mathrm{~s}$ and to visualize themselves undertaking the behavior from their own viewpoint (i.e., "to see the event through your own eyes"). A "beep" sound (length = $1 \mathrm{~s}$ ) signaled them to open their eyes. Five sentences describing selfcontrol events were presented to participants from the self-control group conditions. Five sentences describing simple motor actions were presented to participants in the neutral condition.

Gamble presentation and decision. Participants were offered a $50 \%$ chance of winning $6 €$ and a $50 \%$ chance of losing an amount of money that varied between $2 €$ and $6 €$ (EV ranging from 2 to 0 ). No gamble featured negative EVs. During this stage, participants had to choose to gamble or not, using "Yes" and "No" buttons on each side of the screen. The gambles were not played. Hence, no reward/loss feedback was given to the participants during the gambling task.

Materials. The Coin-Flipping Task (Figure 1A) was programed and ran using E-Prime (v. 2.0.1; Psychology Software Tools, Inc., Pittsburgh, Pennsylvania, USA). The task was presented on a 13-in. computer screen viewed from a distance of approximately $0.5 \mathrm{~m}$. Participants responded to 
Table 2. Sample characteristics for the neutral and the self-control conditions in Studies 2 and 3

\begin{tabular}{|c|c|c|}
\hline & Neutral condition & Self-control condition \\
\hline \multicolumn{3}{|l|}{ Study 2} \\
\hline$n$ & 40 & 40 \\
\hline Proportion of male/female & $17 / 23$ & $18 / 22$ \\
\hline Age & $23.08(5.96)$ & $24.13(5.09)$ \\
\hline Weekly budget (in euros) & $50.00(35.00,70.00)$ & $60.00(30.00,90.00)$ \\
\hline SOGS frequency & $2.00(2.00,4.00)$ & $2.00(0.00,5.00)$ \\
\hline SOGS budget (in euros) & $3.00(3.00,3.00)$ & $3.00(1.00,4.00)$ \\
\hline SOGS severity & $0.00(0.00,1.00)$ & $0.00(0.00,1.00)$ \\
\hline Gambling acceptance & $3.20(2.65,3.60)$ & $3.10(2.25,3.55)$ \\
\hline Motivation for money & $3.00(2.00,5.00)$ & $2.00(2.00,4.00)$ \\
\hline SCL total score frequency & $3.20(0.48)$ & $3.26(0.80)$ \\
\hline SCL total score difficulty & $2.49(0.54)$ & $2.48(0.66)$ \\
\hline BSCS & $2.50(0.50)$ & $2.56(0.37)$ \\
\hline UPPS urgency & $26.71(4.83)$ & $27.60(5.16)$ \\
\hline UPPS lack of premeditation & $20.12(5.06)$ & $20.48(4.29)$ \\
\hline UPPS lack of perseverance & $17.77(3.60)$ & $19.08(3.59)$ \\
\hline UPPS sensation seeking & $32.67(7.39)$ & $33.20(6.61)$ \\
\hline \multicolumn{3}{|l|}{ Study 3} \\
\hline$n$ & 40 & 40 \\
\hline Age & $21.53(2.71)$ & $23.30(5.24)$ \\
\hline Male/female & $16 / 24$ & $18 / 22$ \\
\hline Weekly budget & $37.50(25.00,67.50)$ & $55.00(36.25,80.00)$ \\
\hline SOGS frequency & $2.00(1.00,4.00)$ & $2.50(1.00,4.00)$ \\
\hline SOGS budget & $3.00(1.00,3.00)$ & $3.00(1.00,3.00)$ \\
\hline SOGS severity & $0.00(0.00,1.00)$ & $0.00(0.00,1.00)$ \\
\hline Gambling acceptance & $3.20(2.65,3.60)$ & $3.30(2.40,3.75)$ \\
\hline Motivation for money & $3.00(2.00,4.00)$ & $3.00(2.00,5.00)$ \\
\hline SCL total score frequency & $3.09(0.46)$ & $3.00(0.53)$ \\
\hline SCL total score difficulty & $2.58(0.48)$ & $2.35(0.37)^{* *}$ \\
\hline BSCS & $2.38(0.38)$ & $2.30(0.48)$ \\
\hline UPPS urgency & $28.21(5.02)$ & $27.83(6.47)$ \\
\hline UPPS lack of premeditation & $22.08(4.65)$ & $23.56(4.78)$ \\
\hline UPPS lack of perseverance & $19.69(4.38)$ & $20.71(3.91)$ \\
\hline UPPS sensation seeking & $33.36(5.60)$ & $35.00(6.41)$ \\
\hline
\end{tabular}

Note. Mean and standard deviation (in brackets) are reported for age, SCL scores, BSCS, and UPPS subscales. Median and 25th and 75th percentiles (in brackets) are reported for weekly budget, SOGS scores, gambling acceptance, and motivation for money. SOGS: South Oaks Gambling Screen; SCL: self-control list; BSCS: Brief Self-Control Scale; UPPS: UPPS Impulsive Behavior Scale.

${ }^{* *} p$ value $<.01, p$ values were not corrected for multiple comparisons.

Table 3. List of sentences used in the experiments for the neutral condition (Studies 2 and 3)

A building that contains five levels

An office table that contains two chairs

An elevator that goes up to the second floor

A sheet of paper filled with text

A room painted in white

each trial by pressing one of two buttons on a keyboard, which paralleled buttons on the screen. The choices were to take or not to take the gamble.

Dependent measures. The proportion of "Yes/No" response for each trial was used in order to examine level of gambling acceptance at each gain/loss ratio.

Control measures

Gambling acceptance tendency/predispostion. Participants had to rate on a 5-point scale (ranging from $1=$ never to
$5=$ always), whether they would agree to gamble with their own money in a coin-flipping game, with the following gain/loss ratios: 6(gain)/2(loss), 6/3, 6/4, 6/5, or $6 / 6$. A scale score was calculated as the mean of all items; higher scores indicated higher subjective level of gambling acceptance predisposition.

Motivation for money. We asked participants to report the frequency with which they would pick a $0.20 €$ coin from the street on a 5-point scale, where $1=$ never and 5 = always (Sescousse, Redouté, \& Dreher, 2010).

Trait self-control. Participants completed the BSCS (Tangney et al., 2004).

Impulsivity. The French version of the UPPS (Van der Linden et al., 2006) was administered.

Problem gambling and gambling frequency. We used the 20-item South Oaks Gambling Screen (SOGS; Lesieur \& Blume, 1987) to evaluate participants' gambling-related behavior and problems. The SOGS is a widely used screening instrument for problem gambling and has been 
A.
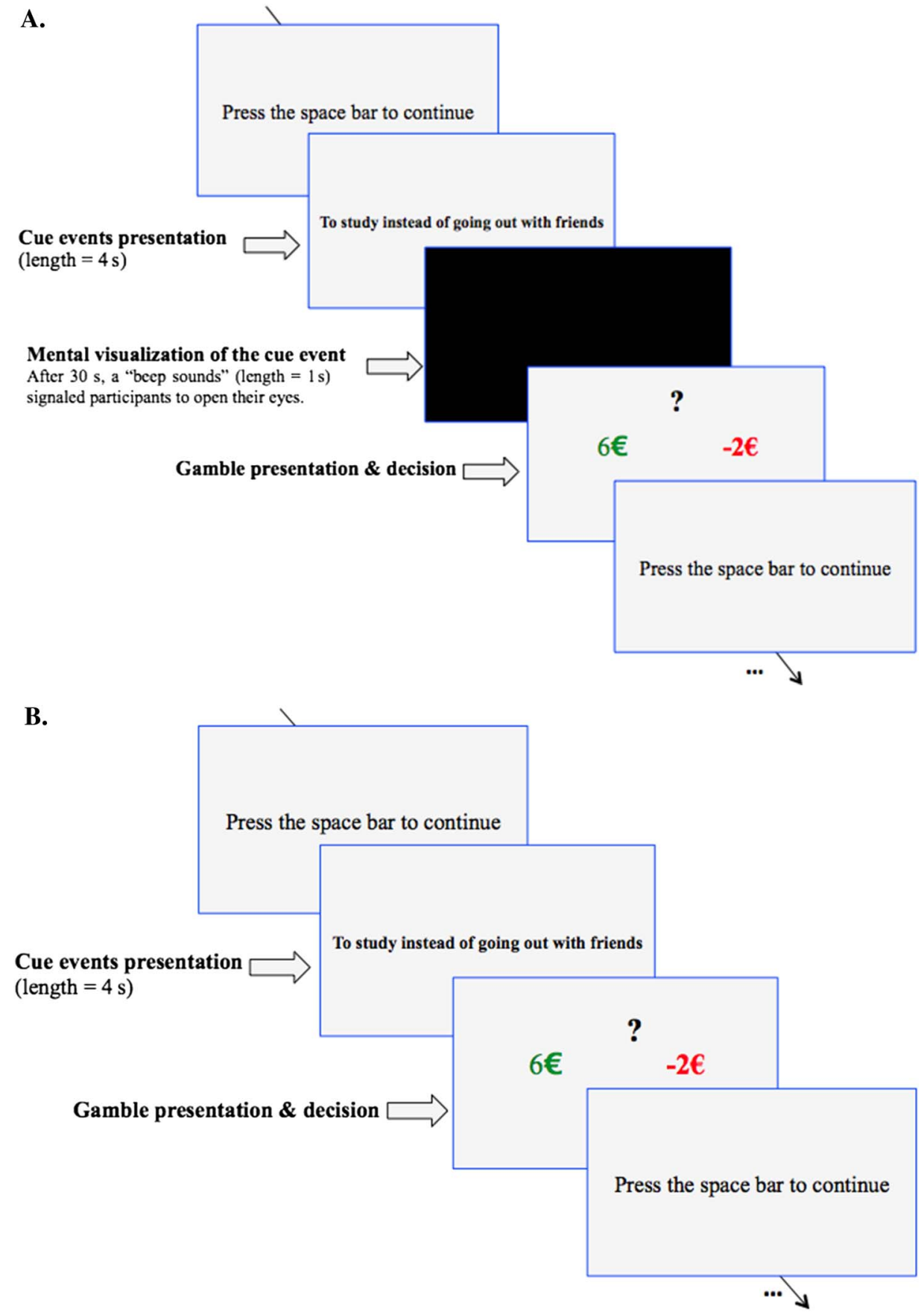

Figure 1. (A) An illustration of a trial from the gambling task used in Study 2. (B) An illustration of a trial from the gambling task used in Study 3

shown to be valid and reliable in community and clinical samples (Lesieur \& Blume, 1987). A total SOGS score of 5 or higher was used to classify participants as probable pathological gamblers or not (scores between 1 and 4 on SOGS typically indicate some problems with gambling; Lesieur \& Blume, 1987).

\section{Procedure}

Preliminary session. Participants first provided informed consent and were assured of the anonymity of their answers. They then filled-out questions capturing demographic information, rated the 30 self-control behaviors on frequency and difficulty, and completed measures of gambling acceptance predisposition and motivation for money. This session was undertaken collectively, approximately 1 -week prior to the laboratory session. Participants received no information on the gambling task featured in the laboratory session.

Laboratory session. Participants were individually tested in a quiet room located at the research unit of the Psychophysiology of Movement at the Faculty of Motor Science of the ULB. Participants first received informed consent and task instructions (specific to their group condition) for the Coin-Flipping Task. All participants received similar task instructions that featured one practice trial in order to 
familiarize them with the task. The term "SENTENCE" was displayed during the cue event presentation of the practice trial. In other words, we did not use either neutral or selfcontrol sentences during the practice trial in order to give similar instructions to participants from the two groups. Importantly, participants were informed that the task included only five trials and that they had a fifty-fifty chance to win $6 €$ or to lose a specific amount that varied across trials. They were then told that a lottery followed the gambling task. During the lottery, participants had to randomly pick one ball (out of five) containing a trial number (i.e., from 1 to 5). The loss or reward corresponded to (a) the participant's decision (to gamble or not) during the gambling task on this specific trial and (b) the amount featured in the specific trial. If the participant decided not to gamble during this trial, they received $6 €$. If participants decided to gamble on a trial, they had to first decide between "head" or "tail," and then the experimenter flipped a coin. Depending on the result of this gamble, the winning or losing amount featured on the trial was added to or withdrawn from the $6 €$ payoff. Hence, participants were remunerated between $0 €$ and $12 €$. This procedure was undertaken in order to ensure that participants' responses were consistent with their true preferences.

After being informed of the lottery procedure, participants performed the gambling task, played the lottery game, and completed the UPPS and SOGS questionnaires. Participants were then remunerated and thanked for their participation (see Figure 2 for a depiction of the experimental procedure.).

\section{Data analyses}

Multivariate analysis of variance (MANOVA) was used to examine between-groups (neutral vs. self-control) difference effect on control measures with normal distributions (the UPPS subscales and the BSCS). Mann-Whitney $U$ tests were used to examine between-group differences in control measures with non-normal distributions (weekly budget, SOGS gambling frequency, SOGS problem gambling severity, SOGS gambling budget, motivation for money, and gambling acceptance predisposition). Independent sample $t$-tests were used for comparing the neutral and the self-control groups on mean scores of frequency and difficulty on the list of 30 self-control behaviors. McNemar's tests were used to examine within-group differences in the proportion of accepted or refused gambles according to the type of trial. Finally, $\chi^{2}$ tests were performed to examine the proportion of participants (between the neutral and the self-control group) who accepted or refused the gamble, separately for the five trials of the gambling game. All $p$ values were adjusted for multiple comparisons with Bonferroni correction.

\section{Ethics}

All procedures performed in studies involving human participants were in accordance with the 1964 Helsinki Declaration and its later amendments or comparable ethical standards. Each participant gave informed consent to the experimental procedure, which was approved by the institutional review board of ULB.

\section{RESULTS AND DISCUSSION}

\section{Characteristics of study participants}

MANOVA revealed that participants from the self-control and the neutral groups did not differ on UPPS subscales and BSCS [Pillai's trace value $=0.08, F(5,73)=0.63, p=.27$ ] Moreover, all pairwise comparisons (Fisher's least significant difference) revealed $p$ values $>$.12. Mann-Whitney $U$ tests revealed that participants from the self-control and the neutral groups did not differ on weekly budget $(U=706.50, Z=-0.54, p=.59)$, SOGS gambling frequency $(U=708.50, Z=-0.71, p=.48)$, SOGS problem gambling severity $(U=762.00, Z=-0.21, p=.83)$, SOGS gambling budget $(U=773.50, Z=-0.07, p=.95)$, motivation for money $(U=681.00, Z=-1.18, p=.24)$, and gambling acceptance predisposition $(U=720.50, Z=-0.77$, $p=.44)$.

Regarding the list of 30 self-control behaviors, the selfcontrol and neutral groups did not differ in self-control difficulty, $t(78)=0.60, p=.74$ and self-control frequency, $t(80)=0.74, p=.71$.

\section{Gambling acceptance (see Table 2 for descriptive statistics)}

McNemar's tests revealed that the proportions of gambles differed between all gambling game trials (all $p<.01$ ), except for between the 6 (gain) $/ 5$ (loss) and the $6 / 6$ trials $(p=1.00$; Figure $3 \mathrm{~A}) \cdot \chi^{2}$ tests revealed that, as compared with the neutral group, a higher proportion of the self-control group accepted the gamble in trials featuring the $6 / 6$ and $6 / 4$ ratios, $\chi^{2}(1, N=80)=13.87, p<.001$; $\chi^{2}(1, N=80)=8.21, p=.02$, respectively (Figure $3 \mathrm{~A}$ ). No between-group differences were observed in the $6 / 2$, $6 / 3$, and $6 / 5$ trials of the gambling game (all $p>.83$; Figure 3A).

Altogether, results from Study 2 are in line with the literature (e.g., Macrae et al., 2014) in showing that mental visualization of effortful self-control events (as compared to neutral situations) increases subsequent gambling acceptance.

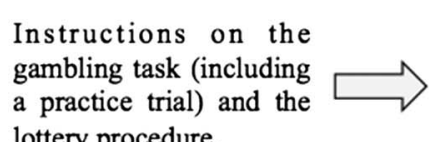

lottery procedure.

\section{Participants Participants} performed the $\longrightarrow$ played the gambling task. $\square$ lottery game.

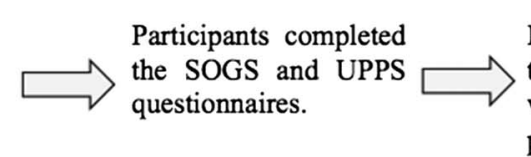

Participants received the remuneration and were thanked for their participation.

Figure 2. Experimental procedure - Studies 2 and 3 

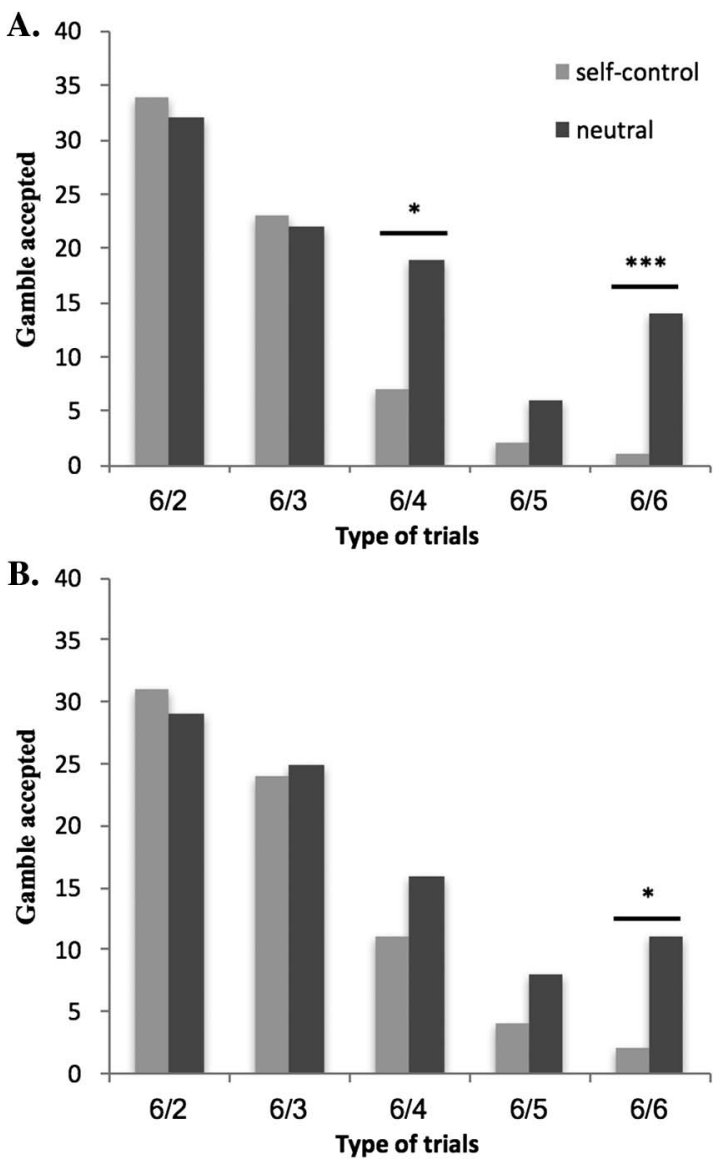

Figure 3. (A) Proportion of gamble accepted in each trial of the gambling task for the self-control and the neutral groups, in Study 2. (B) Proportion of gamble accepted in each trial of the gambling task for the self-control and the neutral groups, in Study 3. $p$ values are being reported for $\chi^{2}$ tests between the neutral and the self-control group, separately for the five trials of the gambling game. All $p$ values were adjusted for multiple comparisons with Bonferroni correction. ${ }^{*} p<.05 .{ }^{* * *} p<.001$

\section{STUDY 3 - METHODS}

\section{Participants}

A new sample of 80 undergraduate students was recruited from the Faculty of Motor Science of ULB. Participants were randomly assigned to the neutral $(n=40)$ or selfcontrol $(n=40)$ gambling task conditions.

\section{Measures}

Selection of cue events. We used the same methods of cue events selection as in Study 2.

The gambling task and experimental conditions. This task was similar to that employed in Study 2, expect for the cue event presentation stage. Specifically, participants viewed five sentences on the computer screen, each for $4 \mathrm{~s}$ (Figure 1B). They were instructed to read (and quietly to themselves) each sentence carefully. In the self-control group condition, sentences focused on self-control events, and in the neutral condition, sentences focused on simple motor actions.
Materials, dependent measures, and control measures. We used similar materials, dependent measures, and control measures as in Study 2.

\section{Procedure}

Preliminary session. We used a similar procedure to those used in Study 2.

Laboratory session. This task was similar to this employed in Study 2, except for task instructions: for each trial of the Coin-Flipping Task, participants were instructed to read the sentence instead of visualizing themselves undertaking the behavior (as in Study 2).

\section{Data analyses}

MANOVA was used to examine between-group (neutral vs. self-control) differences effect on control measures with normal distributions (the UPPS subscales and the BSCS). Mann-Whitney $U$ tests were used to examine betweengroup difference on control measures with a non-normal distribution (weekly budget, SOGS gambling frequency, SOGS problem gambling severity, SOGS gambling budget, motivation for money, and gambling acceptance predisposition). McNemar's tests were used to examine the betweengroup differences in the proportion of accepted or refused gambles according to the type of trial. Finally, $\chi^{2}$ tests were performed to examine the proportion of participants who accepted or refused the gamble, separately for the five trials of the gambling game. All $p$ values were adjusted for multiple comparisons with Bonferroni correction.

\section{Ethics}

All procedures performed in studies involving human participants were in accordance with the 1964 Helsinki Declaration and its later amendments or comparable ethical standards. Each participant gave informed consent to the experimental procedure, which was approved by the institutional review board of ULB.

\section{RESULTS AND DISCUSSION}

\section{Characteristics of study participants (see Table 2 for descriptive statistics)}

MANOVA revealed that participants from the self-control and neutral groups did not differ on UPPS subscales and BSCS [Pillai's trace value $=0.04, F(5,73)=0.66, p=.43$ ] Moreover, all pairwise group comparisons (Fisher's least significant difference) revealed $p$ values $>.17$. MannWhitney $U$ tests revealed that participants from the selfcontrol and the neutral groups did not differ on weekly budget ( $U=600.50, Z=-1.93, p=.06)$, SOGS gambling frequency $(U=784.00, Z=-0.16, p=.88)$, SOGS problem gambling severity $(U=746.50, Z=-0.61, p=.54)$, SOGS gambling weekly budget $(U=786.50, Z=-0.14, p=.89)$, motivation for money $(U=735.50, Z=-0.64, p=.52)$, and gambling acceptance predisposition $(U=778.50$, $Z=-0.21, p=.64)$. 
Regarding the list of 30 self-control behaviors, participants from the neutral group reported higher mean scores of self-control difficulty, as compared to participants from the self-control group, $t(80)=2.47, p=.01$. No difference was observed in the mean score of self-control frequency, $t(80)=0.62, p=.50$.

\section{Gambling acceptance}

McNemar's tests revealed that the proportions of gambling choice differed between all trials of the gambling game (all $p<.001$ ), except between the 6 (gain)/5(loss) and the $6 / 6$ trials $(p=.07)$. Hence, with exception of the trials with the two lowest EV, the higher the EV was, the higher the level of gambling acceptance was (Figure 3B). $\chi^{2}$ tests revealed that, as compared with the neutral group, a higher proportion of participants in the self-control group accepted the gamble in the trial featuring the 6 (gain) $/ 6$ (loss) ratio, $\chi^{2}(1, N=80)=7.44, p=.03$ (Figure 3B). No betweengroup differences were observed in the $6 / 2,6 / 36 / 4$, and $6 / 5$ trials of the gambling game, all $p>.83$ (Figure 3B).

In sum, the results from Study 3 highlighted that the brief apparition of a self-control-related sentence was sufficient for increasing the level of gambling acceptance. Noteworthy, participants from the neutral group reported higher mean scores of self-control difficulty. This might have lowered the impact of the experimental manipulation. Nevertheless, this study design did not allow to examine this research question (i.e., only sentences with higher levels of self-reported difficulty were used in the gambling paradigm). Further studies are thus needed to replicate this study protocol with groups of participants who do not differ on self-reported scores of difficulty to undertake daily-life self-control behaviors. Another complementary alternative would be to examine whether levels of difficulty of daily-life self-control modulate the impact of self-control cues on subsequent monetary risk-taking. For instance, one option would be to implement three experimental conditions: one featuring neutral sentences, one featuring self-control sentences with a low level of self-reported difficulty, and one featuring self-control sentences with a high level of selfreported difficulty.

\section{GENERAL DISCUSSION}

The present paper describes the findings of three complementary studies that aimed at testing the process-model of self-control. Study 1 demonstrated sufficient external validity of a list of self-control events, which were then used in Studies 2 and 3. Next, in line with the strength-model of self-control (Baumeister et al., 1998, 2007), Study 2 highlighted that mental visualization of effortful self-control events increased monetary risk-taking. Finally, Study 3 showed that simply reading sentences related to daily-life self-control was sufficient for increasing monetary risktaking. This last finding provides some support for the process-model of self-control (Inzlicht \& Schmeichel, 2012; Inzlicht et al., 2014) in showing that evoking the content of a "have-to" conduct (i.e., daily-life self-control routines), without its actual enactment, is sufficient for increasing the gravitation toward a "want-to" activity (i.e., gambling). Importantly, in Studies 2 and 3, we observed that the proportion of gambling acceptance was significantly increased in the trial featuring the less advantageous gain/loss ratio [i.e., 6(gain)/6(loss)].

On the whole, the present findings could contribute in advancing knowledge on how the high availability of readyto-consume rewards in modern environments is redefining humans' ability of self-control. Specifically, tempting behaviors have never been so readily available, easy to engage in, and difficult to resist (e.g., Billieux, Schimmenti, Khazaal, Maurage, \& Heeren, 2015; Brevers \& Noël, 2015). This also encompasses activities featuring monetary-risk taking, such as sports betting. Indeed, with easy access from a computer, tablet, or phone, it is possible to bet everywhere, at every moment, such as before or during a game in play, and while simultaneously using different platforms (e.g., Brevers et al., 2018; Hing, Russell, Lamont, \& Vitartas, 2017; Marchica, Zhao, Derevensky, \& Ivoska, 2016). Because it is currently possible to get access to and repeat rewarding "want-to" conducts without engaging in complex cognitive or physical processes, merely thinking of effortful "have-to" conducts could increase gambling temptation and risk-taking in a large range of individuals.

Interestingly, in Study 2, we observed higher levels of gambling acceptance for the trial featuring the $6 / 6$ gain/loss ratios and also for the trial featuring the $6 / 4$ ratios, but not for the trial featuring the $6 / 5$ ratio. This result might be an artifact of the trial-order presentation (e.g., Brevers et al., 2016; Kwak \& Huettel, 2018). Specifically, in this study, the five trials of the Coin-Flipping Task were presented in the following $\mathrm{EV}$-centered succession order $(6 / 2,6 / 5,6 / 6,6 / 4$, and $6 / 3$ ). This procedure was adopted to prevent choices from being driven by the anticipation of trial-order succession that might induce, for instance, strategic or sequential patterns of decision-making in some participants. However, this specific trial order might have induced conservative choices in participants for the trial featuring the $6 / 5$ gain/loss ratio. Indeed, this trial directly followed the one with the $6 / 2$ gain/loss ratio, that is, the trial featuring the highest level of EV. Additional studies are thus needed to replicate findings from Studies 2 and 3 by examining whether trial order can impact the level of gambling acceptance.

One limitation of this study is that we only used gambling (i.e., monetary risk-taking), as an index of "want-to" activity, that is, an equivalent to doing something that is easier or more pleasurable activity. This selection was based on previous studies that used monetary risk-taking as a leisure conduct that could produce strong immediate rewards (Carr \& Steele, 2010; Schmeichel et al., 2010), and showed that participants spent more money after they undertook self-control-related conducts. Nevertheless, for some participants in this study, high-risk wagers might have been flagged as stressful, aversive, and possibly a cognitive burden to undertake (as opposed to a more leisurely or less cognitive-demanding activity). While groups of participants did not differ in the control measures (e.g., self-reported level of gambling acceptance tendency, motivation for money, and gambling frequency), it is still desirable that future research replicates this study with a sample of gamblers, that is, individuals for which gambling is closely 
related to a "want-to" leisure/approach motivation activity. Moreover, it has been highlighted that problem gamblers are characterized by low-trait self-control (e.g., Bergen, NewbyClark, \& Brown, 2012) and by disrupted sensitivity to monetary loss and rewards (e.g., Brevers \& Billieux, 2018; Brevers \& Noël, 2013; van Holst, van den Brink, Veltman, \& Goudriaan, 2010). Hence, recruiting a sample of gamblers, ranging from non-problem to high-problem gambling, should allow to examine whether levels of trait selfcontrol sensitivity to loss and rewards could modulate the impact of self-control cues on monetary risk-taking.

Future research should also examine whether comparable increases of monetary risk-taking occur during simultaneous self-control. Indeed, in contrast to sequential self-control (which is used in this study), it has been shown that exerting effortful self-control in one domain facilitates simultaneous self-control performance in unrelated domains (Tuk, Zhang, \& Sweldens, 2015). This effect has been referred to as "inhibitory spillover" (Berkman, Burklund, \& Lieberman, 2009) or "transfer of cautiousness" (Verbruggen, Adams, \& Chambers, 2012). Specifically, when people engage in a "have-to" task and inhibit a focal impulse, it facilitates the inhibition of other impulses as well (e.g., proactive motor response inhibition diminishes monetary risk-taking while gambling; Stevens et al., 2015; Verbruggen et al., 2012). Therefore, it would be interesting to examine whether the onset of self-control-related sentences differently impact monetary risk-taking when it is presented before (sequential order) or during (simultaneously to) gambling.

Additional studies are also needed in order to test whether the reading of self-control related sentences influence the level of monetary risk-taking during a gambling task, featuring a higher number of repeated gambling choices, and with varying levels of gain-loss probability (e.g., the Cups Task; Weller, Levin, Shiv, \& Bechara, 2007). Indeed, in this study, the Coin-Flipping Task only included a single "Yes/No" response trial for each EV context. This might have lowered the statistical power of the observed effects and hampered direct comparisons of gambling acceptance across gain/loss ratios. Moreover, all trials featured a similar 0.50 gain-loss probability. Hence, the present results may not be generalizable to other gain-loss probability contexts.

Another limitation is that self-control sentences featured different types of "have-to" conducts. For instance, "to buy a fruit instead of a candy" involves health-related goals, whereas "to study instead of going out with friends" involves professional-related goals. Hence, future studies should examine whether the type of "have-to" conducts could differently impact the "want-to" conducts. Moreover, in contrast to the self-control sentences, the neutral sentences were not individualized. This might have lowered the impact of the experimental manipulation. In addition, the effects observed in the present studies could also be explained by other processes that are not related to either the process or strength models of self-control. For example, when individuals mentally visualized daily-life self-control or read self-control sentences, it might have triggered a sense of overconfidence in the individual, so that they briefly believed that their choices (e.g., in the gambling paradigm) were more likely to be right, even in riskier circumstances. Further studies are needed to explore this assumption. Finally, notwithstanding the effects revealed herein, it remains to be seen whether imagined self-control (as in Study 2) triggers effects on monetary risk-taking comparable to actual execution of self-control behavior. This issue merits further research.

In sum, we show that the viewing of sentences evoking daily-life effortful self-control, as compared to viewing neutral sentences, can increase subsequent monetary risktaking. These findings provide initial support for the "process-model" of self-control, which posits that egodepletion can be induced by a switch of interest between "have-to" and "want-to" conducts, rather than by a decrease of cognitive resources.

Funding sources: This work was supported by the National Center for Responsible Gaming (NCRG; Early Stage Investigator Grant) and the Belgian National Funds for Scientific Research (FNRS; Chargé de Recherche Grant).

Authors' contribution: DB, JF, OT, AnaB, MA, PV, CK, and AntB designed the study and wrote the protocol. DB conducted literature searches and provided summaries of previous research studies. DB, JF, AnaB, and MA recruited the participants and collected the data. DB, OT, AnaB, and MA conducted the statistical analysis. DB wrote the first draft of the manuscript and all authors contributed to and have approved the final version of the manuscript.

Conflict of interest: The authors report no financial or other relationship relevant to the subject of this article.

\section{REFERENCES}

Alberts, H. J. E. M., Martijn, C., \& de Vries, N. K. (2011). Fighting self-control failure: Overcoming ego depletion by increasing self-awareness. Journal of Experimental Social Psychology, 47(1), 58-62. doi:10.1016/j.jesp.2010.08.004

Baumeister, R. F., Bratslavsky, E., Muraven, M., \& Tice, D. M. (1998). Ego depletion: Is the active self a limited resource? Journal of Personality and Social Psychology, 74(5), 12521265. doi:10.1037/0022-3514.74.5.1252

Baumeister, R. F., Vohs, K. D., \& Tice, D. M. (2007). The strength model of self-control. Current Direction in Psychological Science, 16(6), 351-355. doi:10.1111/j.1467-8721.2007.00534.x

Bergen, A. E., Newby-Clark, I. R., \& Brown, A. (2012). Low trait self-control in problem gamblers: Evidence from self-report and behavioral measures. Journal of Gambling Studies, 28(4), 637-648. doi:10.1007/s10899-011-9274-9.

Berkman, E. T., Burklund, L., \& Lieberman, M. D. (2009). Inhibitory spillover: Intentional motor inhibition produces incidental limbic inhibition via right inferior frontal cortex. Neurolmage, 47(2), 705-712. doi:10.1016/j.neuroimage.2009.04.084

Billieux, J., Schimmenti, A., Khazaal, Y., Maurage, P., \& Heeren, A. (2015). Are we overpathologizing everyday life? A tenable blueprint for behavioral addiction research. Journal of Behavioral Addictions, 4(3), 119-123. doi:10.1556/2006. 4.2015.009 
Blain, B., Hollard, G., \& Pessiglione, M. (2016). Neural mechanisms underlying the impact of daylong cognitive work on economic decisions. Proceedings of the National Academy of Sciences of the United States of America, 113(25), 6967-6972. doi:10.1073/pnas.1520527113

Botvinick, M. M. (2007). Conflict monitoring and decision making: Reconciling two perspectives on anterior cingulate function. Cognitive, Affective \& Behavioral Neuroscience, 7(4), 356-366. doi:10.3758/CABN.7.4.356

Brevers, D., \& Billieux, J. (2018). Le jeu pathologique: un trouble des processus impliqués dans la prise de décision? [Pathological gambling: A disorder of decision-making processes?] In P. Denis (Ed.), Droit des jeux de hazard (pp. 161-190). Belgium: Edition Larcier Group.

Brevers, D., Foucart, J., Verbanck, P., \& Turel, O. (2017). Examination of the validity and reliability of the French version of the Brief Self-Control Scale. Canadian Journal of Behavioural Science, 49(4), 243-250. doi:10.1037/cbs0000086

Brevers, D., Herremans, S. C., He, Q., Vanderhasselt, M. A., Petieau, M., Verdonck, D., De Wite, S., Poppa, N., Kornreich, C., Bechara, A., \& Baeken, C. (2018). Facing temptation: The neural correlates of gambling availability during sport picture exposure. Cognitive, Affective, and Behavioral Neuroscience, 18(4), 718-729. doi: 10.3758/s13415-018-0599-z

Brevers, D., \& Noël, X. (2013). Pathological gambling and the loss of willpower: A neurocognitve perspective. Socioaffective and Neuroscience Psychology, 3(1), 21592. doi:10.3402/snp. v3i0.21592

Brevers, D., \& Noël, X. (2015). Commentary on: Are we overpathologizing everyday life? A tenable blueprint for behavioral addiction research. On functional and compulsive aspects of reinforcement pathologies. Journal of Behavioral Addictions, 4(3), 135-138. doi:10.1556/2006.4.2015.017

Brevers, D., Noel, X., Clark, L., Zyuzin, J., Justin Park, J., \& Bechara, A. (2016). The impact of precommitment on risk-taking while gambling: A preliminary study. Journal of Behavioral Addictions, 5(1), 51-58. doi:10.1556/2006.5. 2016.008

Carr, P. B., \& Steele, C. M. (2010). Stereotype threat affects financial decision making. Psychological Science, 21(10), 1411-1416. doi:10.1177/0956797610384146

Converse, P. D., \& Deshon, R. P. (2009). A tale of two tasks: Reversing the self-regulatory resource depletion effect. The Journal of Applied Psychology, 94(5), 1318-1324. doi:10.1037/ a0014604

Dang, J., Xiao, S., \& Dewitte, S. (2014). Self-control depletion is more than motivational switch from work to fun: The indispensable role of cognitive adaptation. Frontiers in Psychology, 5, 933. doi:10.3389/fpsyg.2014.00933

Duckworth, A. L., Gendler, T. S., \& Gross, J. J. (2016). Situational strategies for self-control. Perspectives on Psychological Science, 11(1), 35-55. doi:10.1177/1745691615623247

Fischer, P., Kastenmüller, A., \& Asal, K. (2012). Ego depletion increases risk-taking. The Journal of Social Psychology, 152(5), 623-638. doi:10.1080/00224545.2012.683894

Fujita, K. (2011). On conceptualizing self-control as more than the effortful inhibition of impulses. Personality and Social Psychology Review, 15(4), 352-366. doi:10.1177/10888683 11411165

Galla, B. M., \& Duckworth, A. L. (2015). More than resisting temptation: Beneficial habits mediate the relationship between self-control and positive life outcomes. Journal of Personality and Social Psychology, 109(3), 508-525. doi: $10.1037 /$ pspp0000026

Goldfarb, L., \& Henik, A. (2007). Evidence for task conflict in the Stroop effect. Journal of Experimental Psychology. Human Perception and Performance, 33(5), 1170-1176. doi:10.1037/ 0096-1523.33.5.1170

Goldfarb, L., \& Henik, A. (2013). The effect of a preceding cue on the conflict solving mechanism. Experimental Psychology, 60(5), 347-353. doi:10.1027/1618-3169/a000205

Goldfarb, L., \& Henik, A. (2014). Is the brain a resourcecheapskate? Frontiers in Human Neuroscience, 8, 857. doi:10.3389/fnhum.2014.00857

Hagger, M. S., Wood, C., Stiff, C., \& Chatzisarantis, N. L. D. (2010). Ego depletion and the strength model of self-control: A meta-analysis. Psychological Bulletin, 136(4), 495-525. doi:10.1037/a0019486

Hing, N., Russell, A. M. T., Lamont, M., \& Vitartas, P. (2017). Bet anywhere, anytime: An analysis of Internet sports bettors' responses to gambling promotions during sports broadcasts by problem gambling severity. Journal of Gambling Studies, 33, 1051-1065. doi:10.1007/s10899-017-9671-9

Hockey, G. R. J., \& Earle, F. (2006). Control over the scheduling of simulated office work reduces the impact of workload on mental fatigue and task performance. Journal of Experimental Psychology. Applied, 12(1), 50-65. doi:10.1037/1076898X.12.1.50

Imhoff, R., Schmidt, A. F., \& Gerstenberg, F. (2014). Exploring the interplay of trait self-control and ego depletion: Empirical evidence for ironic effects. European Journal of Personality, 28(5), 413-424. doi:10.1002/per.1899

Inzlicht, M., \& Schmeichel, B. J. (2012). What is ego depletion? Toward a mechanistic revision of the resource model of selfcontrol. Perspectives on Psychological Science, 7(5), 450-463. doi:10.1177/1745691612454134

Inzlicht, M., Schmeichel, B. J., \& Macrae, C. N. (2014). Why selfcontrol seems (but may not be) limited. Trends in Cognitive Sciences, 18(3), 127-133. doi:10.1016/j.tics.2013.12.009

Johnson, S. L., Carver, C. S., Mulé, S., \& Joormann, J. (2013). Impulsivity and risk for mania: Towards greater specificity. Psychology \& Psychotherapy: Theory, Research \& Practice, 86(4), 401-412. doi:10.1111/j.2044-8341.2012. 02078.x

Kiesel, A., Steinhauser, M., Wendt, M., Falkenstein, M., Jost, K., Philipp, A. M., \& Koch, I. (2010). Control and interference in task switching - A review. Psychological Bulletin, 136(5), 849-874. doi:10.1037/a0019842

Kool, W., \& Botvinick, M. (2014). A labor/leisure tradeoff in cognitive control. Journal of Experimental Psychology. General, 143(1), 131-141. doi:10.1037/a0031048

Kool, W., McGuire, J. T., Rosen, Z. B., \& Botvinick, M. M. (2010). Decision making and the avoidance of cognitive demand. Journal of Experimental Psychology. General, 139(4), 665-682. doi:10.1037/a0020198

Kwak, Y., \& Huettel, S. (2018). The order of information processing alters economic gain-loss framing effects. Acta Psychologica, 182, 46-54. doi:10.1016/j.actpsy.2017.11.013

Lesieur, H. R., \& Blume, S. B. (1987). The South Oaks Gambling Screen (SOGS): A new instrument for the identification of pathological gamblers. The American Journal of Psychiatry, 144(9), 1184-1188. doi:10.1176/ajp.144.9.1184 
Macrae, C. N., Christian, B. M., Golubickis, M., Karanasiou, M., Troksiarova, L., McNamara, D. L., \& Miles, L. K. (2014). When do I wear me out? Mental simulation and the diminution of self-control. Journal of Experimental Psychology. General, 143(4), 1755-1764. doi:10.1037/a0036100

Marchica, L., Zhao, Y., Derevensky, J., \& Ivoska, W. (2016). Understanding the relationship between sports-relevant gambling and being at-risk for a gambling problem among American adolescents. Journal of Gambling Studies, 33(2), 437-448. doi:10.1007/s10899-016-9653-3

Miller, J. D., Campbell, W. K., Young, D. L., Lakey, C. E., Reidy, D. E., Zeichner, A., \& Goodie, A. S. (2009). Examining the relations among narcissism, impulsivity, and self-defeating behaviors. Journal of Personality, 77(3), 761-794. doi:10.1111/j.1467-6494.2009.00564.x

Moller, A. C., Deci, E. L., \& Ryan, R. M. (2006). Choice and egodepletion: The moderating role of autonomy. Personality \& Social Psychology Bulletin, 32(8), 1024-1036. doi:10.1177/ 0146167206288008

Moulton, S. T., \& Kosslyn, S. M. (2009). Imagining predictions: Mental imagery as mental emulation. Philosophical Transactions of the Royal Society B, 364(1521), 1273-1280. doi:10.1098/rstb.2008.0314

Muraven, M., \& Slessareva, E. (2003). Mechanisms of self-control failure: Motivation and limited resources. Personality \& Social Psychology Bulletin, 29(7), 894-906. doi:10.1177/ 0146167203029007008

Nolet, K., Rouleau, J.-L., Benbouriche, M., Carrier Emond, F., \& Renaud, P. (2015). How ego depletion affects sexual self-regulation: Is it more than resource depletion? Journal of Sex Research, 53(8), 994-1007. doi:10.1080/00224499.2015. 1096887

Salmon, S. J., Adriaanse, M. A., Fennis, B. M., De Vet, E., \& De Ridder, D. T. D. (2016). Depletion sensitivity predicts unhealthy snack purchases. Appetite, 96, 25-31. doi:10.1016/j. appet.2015.08.027

Schmeichel, B. J., Harmon-Jones, C., \& Harmon-Jones, E. (2010). Exercising self-control increases approach motivation. Journal of Personality and Social Psychology, 99(1), 162-173. doi:10.1037/a0019797

Sescousse, G., Redouté, J., \& Dreher, J.-C. (2010). The architecture of reward value coding in the human orbitofrontal cortex. The Journal of Neuroscience, 30(39), 13095-13104. doi:10.1523/JNEUROSCI.3501-10.2010

Stevens, T., Brevers, D., Chambers, C. D., Lavric, A., McLaren, I. P. L., Mertens, M., Noël, X., \& Verbruggen, F. (2015). How does response inhibition influence decision making when gambling? Journal of Experimental Psychology. Applied, 21(1), 15-36. doi:10.1037/xap0000039

Tangney, J. P., Baumeister, R. F., \& Boone, A. L. (2004). High self-control predicts good adjustment, less pathology, better grades, and interpersonal success. Journal of Personality, 72(2), 271-324. doi:10.1111/j.0022-3506.2004.00263.x

Tsukayama, E., Duckworth, A. L., \& Kim, B. (2012). Resisting everything except temptation: Evidence and an explanation for domain-specific impulsivity. European Journal of Personality, 26(3), 318-334. doi:10.1002/per.841

Tsukayama, E., Duckworth, A. L., \& Kim, B. (2013). Domainspecific impulsivity in school-age children. Developmental Science, 16(6), 879-893. doi:10.1111/desc.12067

Tuk, M. A., Zhang, K., \& Sweldens, S. (2015). The propagation of self-control: Self-control in one domain simultaneously improves self-control in other domains. Journal of Experimental Psychology. General, 144(3), 639-654. doi:10.1037/xge0000065

Van der Linden, M., d'Acremont, M., Zermatten, A., Jermann, F., Larøi, F., Willems, S., Juillerat, A. C., \& Bechara, A. (2006). A French adaptation of the UPPS Impulsive Behavior Scale: Confirmatory factor analysis in a sample of undergraduate students. European Journal of Psychological Assessment, 22(1), 38-42. doi:10.1027/1015-5759.22.1.38

van Holst, R. J., van den Brink, W., Veltman, D. J., \& Goudriaan, A. E. (2010). Why gamblers fail to win: A review of cognitive and neuroimaging findings in pathological gambling. Neuroscience and Biobehavioral Reviews, 34(1), 87-107. doi:10.1016/j.neubiorev.2009.07.007

Verbruggen, F., Adams, R., \& Chambers, C. D. (2012). Proactive motor control reduces monetary risk taking in gambling. Psychological Science, 23(7), 805-815. doi:10.1177/ 0956797611434538

Wegner, D. M. (1994). Ironic processes of mental control. Psychological Review, 101(1), 34-52. doi:10.1037/0033295X.101.1.34

Weller, J. A., Levin, I. P., Shiv, B., \& Bechara, A. (2007). Neural correlates of adaptive decision making for risky gains and losses. Psychological Science, 18(11), 958-964. doi:10.1111/ j.1467-9280.2007.02009.x

Whiteside, S. P., \& Lynam, D. R. (2001). The five factor model and impulsivity: Using a structural model of personality to understand impulsivity. Personality and Individual Differences, 30(4), 669-689. doi:10.1016/S0191-8869(00)00064-7

Wilson, M. (2002). Six views of embodied cognition. Psychonomic Bulletin \& Review, 9(4), 625-636. doi:10.3758/ BF03196322 